\title{
EDITORIAL
}

\section{The clinical significance of dysprosody ${ }^{1}$}

Most languages are endowed with a distinctive accentual system or, better, a pattern of intonation. On tuning in to a foreign station it may be easy to detect that the speaker is broadcasting in one of the Scandinavian tongues, even for one who is conversant with no language other than English. He may be sensitive enough to realize that it is Norwegian that he is hearing rather than Swedish or Danish. Few would confuse French with German, or even with Italian or Spanish. A Welshman employs the same chanson de parler whether he is taking in English or in Cymric. These facts are so because each speech-melody is racially or rather geographically specific, and bears no necessary relationship either with feeling-tone or with meaning.

Before discussing anomalies of this 'third element of speech', as it has been called, it must be borne in mind that emotional factors may distort the prosody of speech through alterations in volume, pitch and tempo. Interpretation may be simple, but not always so, for it is sometimes unsafe to gauge the speaker's mood when the words are not understood. The loud and violent diction of some foreigners may be erroneously taken as evidence of anger.

The intonational pattern may furthermore be meaningful. Placement of the stress is often allimportant, as in the five-word sentence 'that man is a nuisance'. Thus:

\section{that man is a nuisance \\ that man is a nuisance \\ that man is a nuisance \\ that man is a nuisance}

look identical in print but differ widely in significance according to which word is emphasized.

It is evident, therefore, that three distinct patterns of intonation can be identified in spoken speech, which may be spoken of as (1) the innate, or geographically specific; (2) the emotional; and (3) the semantic. In some regions communication may be effected not by the ordinary tracheolaryngeal route but by whistling. This in turn depends upon the characteristic melody of the language of the environment. Thus the Silbo of the Canary Islands is no more than whistled Spanish, just as in Sierra Leone the local whistle-talk is based upon the Mende.

In some languages alterations in tone are entirely semantic. Chinese is the best known instance of a polytonic language being made up of a mere 420 monosyllables. These are not homophones, however, for the meaning depends upon the differences in the way they are sounded. In the Mandarin dialect there are four distinct tonemes, tones, or Chêng. These are all-important in speech. Thus a monosyllable transcribed in English as 'chu' stands for pig, bamboo, God, or residing, according to which tonal inflection is employed. Again, 'mai' means either to buy or to sell, according to its tonal quality. The Cantonese dialect contains as many as nine discernable tones. In the Annamitic variant of Chinese the phrase 'ba bà bâ bá', if correctly pronounced, means 'Three ladies boxed the ear of the Prince's favourite' (Max Müller).

In other parts of the world, the spoken languages are bitonal. Bitonality is the basis of the African drum-talk. High and low tones in speech are represented by beats upon drums of two different sizes. Thus in the Kele language the sentence 'the child has neither father nor mother' (Wana ati la sango la nyango) would be transmitted in drum-talk as HL. LH. L. HH. L. LH., where $\mathrm{H}$ represents a high tone and $\mathrm{L}$ a low one.

Ambiguity is avoided by a two-fold process of repetition, supplemented by considerable amplification.

In Kele, for example, the word for father (sango) comprises two high tones; but at least 130

1 Address for correspondence: Dr Macdonald Critchley, The National Hospital, Queen Square, London WCIN 3BG. 
other words in that language have a similar tonal pattern. To ensure that the word 'father' is understood by the listener, explanatory or qualifying phrases are added, just as in the case of Chinese. For example, the word likonda means banana, but to clarify the drum-passage the signaller adds 'the manioc which is propped up high'. 'Money' is transmitted by the phrase 'the pieces of metal which arrange palavers'. A 'dead body' is 'a corpse lying on its back on the clods of earth'. Drum-messages are therefore slower to transmit than spoken speech.

Western medicine is well-nigh ignorant of states of dysprosody affecting tonal languages. A pre-war exception is the work of Lyman, Li and Hsü on the behaviour of the Chêng in Chinese aphasiacs in Peiping. They found that in their truncated speech the tonal properties remained intact provided that articulation was not impaired.

Turning to the question of pathological prosodic changes in Western tongues, it is possible to detect (1) an ablation of the intonational pattern; and (2) dysprosody, whereby the conventional speech-melody becomes altered.

The most commonplace example of an aprosodic speech is met with in Parkinsonism. The monotonous character may be linked with small-range lip-movements, reduced volume, verbal festination, and sometimes palilalia. Other and rarer examples have also been described of loss of verbal intonation as the result of disease.

I have observed several cases of dysprosody developing in English aphasiacs. Oddly enough, in the stage of speech-resolution the patient has been mistakenly regarded as Welsh. There was a case in point where the aphasia had been due to a brain injury resulting from a traffic accident. The victim's claim was settled in the Law Courts and the Press made considerable play of the financial award which compensated a Londoner for the development of a Welsh accent.

Dysprosody may take the form of a re-emergence of a foreign accent in a bilingual who, prior to the stroke, had spoken two languages with equal proficiency. This I have observed more than once in residents in Great Britain who were of Anglo-French origin. During convalescence the patients betrayed an obvious French accent which had not been present before the stroke. Professor Alajouanine of Paris has told me that in France an educated aphasiac may talk like a foreigner English, German or Belgian, in that order.

Monrad-Krohn, who was the first to draw the attention of neurologists to the prosodic elements of speech, described the case of a lady who, while convalescent from an aphasia, developed an unexpected method of speaking. As a Norwegian living through the German occupation of the country, she found herself cold-shouldered when shopping, for she was mistaken for a German.

More down to earth is the phenomenon of a regional accent emerging in an aphasiac, whose boyhood habit of speaking had been laboriously erased by teachers of elocution. With the onset of aphasia one could detect the re-emergence of the lower-class speech-pattern of his early days.

This last-named occurrence illustrates the typical release of inhibition so commonly exhibited by aphasiacs in their utterances. Dysprosody in general remains an obscure problem in speechpathology, but one which merits considerably more attention than it has so far received. 